\title{
Palabras inaugurales en XVIII Jormnada Universitaria de Desarrollo Científico (JUDC) de FAREM-Estelí
}

\author{
MSc. Máximo Rodriguez Pérez ${ }^{1}$
}

Señoras y señores

La inauguración de una nueva Jornada Científica en nuestra Facultad, en este aso la número XVIII es siempre motivo de una profunda satisfacción.

Representa un momento de camaradería, de debate académico y de puesta al día de los problemas centrales de los diferentes temas que estaremos abordando (medio ambiente, cambio climático, administración CPF economía, educación, ingenierías, turismo etc.

En esta jornada tendremos distribuidas en cuatro días 16 mesas temáticas, con 186 trabajos, 526 estudiantes y 42 tutores y tutoras. Esta es una jornada histórica en la facultad por la cantidad de trabajos, mesas y participación de estudiantes y docentes, lo cual representa el 13\% de la cantidad de estudiantes que tenemos este año. Este año por primera vez tendremos una Mesa de Inglés, Mesa de Educación Inicial y Mesa de Agroindustria .. Bajo el lema "Caminando al éxito: investigando, innovando y emprendiendo".

Siento, sinceramente, un gran honor de ser partícipe de esta Jornada en el rol de Decano de las mismas. Y me resulta más que gratificante el hecho, al advertir que este encuentro científico es producto, en gran medida, de muchos esfuerzos particulares sumados, tanto de los estudiantes de las diferentes carreras que servimos en nuestra facultad, de mis colegas docentes y esto no sería posible también sin el trabajo del personal técnico y personal administrativo de nuestra Facultad.

Los diversos temas que se abordaran estos días son una muestra más que suficiente, de que las inquietudes existen en nuestros estudiantes y docentes de nuestro facultad y de que asistimos a una jornadas universitaria científica muy productiva, como continuidad próspera de un encuentro académico que ha ido consolidándose con el paso de los años, y que, seguramente, seguirá afirmándose en las jornadas venideras, aunque la tarea nos resulte o nos parezca, cada vez más ardua y el desafío nos parezca cada vez mayor.

Con el lema de "Caminando al éxito: investigando, innovando y emprendiendo" hemos intentado resumir el espíritu que pretendimos imponerle a estas Jornadas. Consideramos - y sirva de ejemplo lo siguiente - que es sumamente importante el saber hacer, saber aprender, saber aprehender y lo más importante saber hacer ciencia con conciencia.

1 Decano FAREM-Estelí/UNAN-Managua. Correo Electrónico: max.andrei.rodriguez@gmail.com 
Quiero expresar mi más profundo respeto a todo el personal docente administrativo y por supuesto a nuestros estudiantes, con los cuales nos ha tocado compartir de distintas maneras, gran parte de nuestra vida académica. Esta mañana, y mientras pensaba las palabras que iba a decir en este pequeño discurso, recordé un consejo que le dio un jefe a un director de hospital: "Si un hospital no respeta a sus médicos más viejos, carece de identidad. Y si no respeta a sus médicos más jóvenes, carece de futuro".

\section{Lo que para nosotros se traduciría en: "Si en nuestra universidad no se respeta a los profesores mayores, se carece de identidad. Y si no se respeta a sus profesores más jóvenes, carecemos de futuro".}

El tiempo, nos dará la razón.

Por alguna razón, a las universidades les pasa lo mismo que les pasa a las personas. En cada momento de sus vidas, son lo que ya fueron, y son, lo que terminaran siendo. La ciencia de hoy, es lo que hicieron de ella, miles de personas. Pero también es, lo que terminará siendo mañana, gracias a las personas que hoy lo hacemos.

Los retos que imponen las nuevas tecnologías, junto a los avances de las investigaciones que se realizan, cambiarán de manera espectacular en los próximos años algunas partes de la ciencia, tal y como hoy la conocemos.

En nuestra universidad le damos gran importancia a la realización de jornadas científicas como las que hoy nos ocupa, ya que consideramos que estamos viviendo un momento especialmente interesante para la investigación, y reuniones como ésta favorecen, difunden y amplían nuestros conocimientos.

La emoción de crear constituye un aliciente que impulsa infatigablemente en la búsqueda de lo nuevo. Para el investigador motivado, se esfuman con frecuencia las nociones de tiempo y de lugar. En la labor creadora no se trata de cumplir un horario de trabajo y de satisfacer un mínimo de requerimientos formales; se persigue al contrario, expresarse aún a costa de sacrificios en una obra que conlleva mucho esfuerzo y trabaja intelectual. Cuando esa inquietud está además animada por el deseo de que el logro perseguido contribuya a hacer ciencia con conciencia y de configurar una vida más feliz y hermosa para los semejantes, se intensifica y ahonda la satisfacción espiritual que acompaña la creación científica después de muchas horas de estudios y de trabajo arduo.

Fundamental objetivo de la tarea universitaria es la búsqueda de la verdad, nuestra universidad, "se conoce y se amplía con la investigación, se transmite mediante la docencia y se hace cultura al difundirse en su entorno social; no es cabalmente universidad aquella que renuncia a la investigación. Así mismo la participación de estudiantes en la tarea investigadora tiene un efecto beneficioso para 
la vida universitaria, pues ellos pueden aportar ideas creativas y originales, porque se fomentan vocaciones universitarias que tomarán el relevo más adelante y porque ese trato continuo, sincero y respetuoso entre docente, investigador y estudiante, es la mejor escuela de aprendizaje ya que es en la convivencia donde se forma la persona humana.

Crear espacios como el que constituye esta jornada para que nuestra Facultad difunda las experiencias de investigación realizadas por profesores y por estudiantes de grado y en otras jornadas de postgrados, es comulgar con los planteamientos que siempre hemos creído, en ese binomio docente- estudiante y ha colocado su empeño en transitar hacia el encuentro de la verdad, no como un privilegio de quien enseña sino como una labor colectiva en la que el universitario en formación debe asumir también un papel protagónico. La labor creadora junto a la siembra del saber es entonces la esencia de la institución universitaria.

Los temas que tienen impacto en el bienestar social y económico de nuestro entorno son tarea obligada de la universidad, así a través de la investigación podrán surgir las respuestas a las interrogantes que nuestra sociedad se plantea, esto significa que sin obviar lo que conocemos, la investigación debe orientarse hacia los problemas vigentes y sus resultados deben ser de utilidad.

Hacer investigación científica, tecnológica o de contenido social que cumpla con la condición de ser original y produzca resultados de calidad, constituye en estos momentos un enorme reto para los profesores y estudiantes investigadores universitarios, que contemplan la investigación como una de sus funciones esenciales.

Consideramos que esta es una oportunidad propicia para llamar la atención sobre la necesidad de generar políticas públicas que, impulsen positivamente la capacidad de generar conocimiento nuevo, que es función irrenunciable de la universidad.

Durante estos días evidenciará nuestra Facultad Regional Multidisciplinaria de Estelí, la efectividad de su quehacer. Por ello nos satisface de manera intensa el organizar este tipo de eventos que, reconfortan el espíritu universitario.

Finalizamos nuestra intervención recordando, por pertinentes las frases de Juan Pablo segundo que dijo:

\section{"De quien trabaja en el ámbito de la investigación científica, dependen en gran parte la renovación de nuestra sociedad y la construcción de un futuro de paz mejor para todos".}

Me congratulo entonces de inaugurar este evento especial de uno de nuestros principales quehaceres universitarios como es la investigación, y estoy seguro que estos días compartiremos reflexiones, debates, intercambio de ideas en un ámbito de exposición y discusión pluralista, porque creo 
que así lo debemos valorar cada uno de los aquí presentes - que es a partir del intercambio de conocimientos, del estudio profundo de los problemas que nos son comunes, de la investigación y de los balances y estrategias consensuadas, que el futuro del complejo desarrollo económico y social de nuestra región y de nuestro país, puede llegar aún feliz término lo que tanto deseamos, como es la erradicación de la pobreza económica, educativa, social y lo principal la pobreza mental que tanto nos atrasa en el desarrollo humano.

Muchas Gracias 